\title{
Can process accountability mitigate myopic biases? An experimental analysis
}

\section{Mina Ličen ${ }^{1} \mathbb{D} \cdot$ Sergeja Slapničar ${ }^{2}$}

Accepted: 2 November 2021 / Published online: 1 January 2022

(c) Crown 2021

\begin{abstract}
This paper examines the impact of process accountability on two biases causing myopic or short-sighted decision making. These biases are strong preferences for immediate and certain outcomes known as delay and risk aversion. We hypothesize that accountability alone is insufficient to undo the biases, but if coupled with a cue on subjective discount rates, it will attenuate biases. To analyze our research question, we used a within- and between-subjects experimental design (two accountability conditions compared with a non-accountability condition and with each other) with delay and probability discounting choice tasks involving 118 students of accounting, finance and management in an online experiment. In line with our hypotheses, we find that process accountability successfully reduces excessive delay and risk aversion only if it provides a cue about the subjective discount rate. We discuss the implications of our findings for management control.
\end{abstract}

Keywords Process accountability $\cdot$ Justification pressure $\cdot$ Cognitive bias $\cdot$ Myopic decision-making $\cdot$ Delay aversion $\cdot$ Risk aversion $\cdot$ Time preference

JEL Classification D87 · M41 · M48

\section{Introduction}

Managers regularly make decisions in which they have to weigh current costs against the future benefits for an organization. For example, they compare immediate cash outflows with uncertain future cash inflows when deciding on investment.

Mina Ličen

mina.licen@ef.uni-lj.si

Sergeja Slapničar

s.slapnicar@business.uq.edu.au

1 School of Economics and Business, University of Ljubljana, Kardeljeva pl. 17, 1000 Ljubljana, Slovenia

2 The University of Queensland Business School, Australia, Brisbane, QLD 4072, Australia 
They weigh short-term profits against uncertain long-term returns when deciding on marketing campaigns and the immediate costs against long-term benefits when deciding on research and development projects. It is very complex to make these compromises, as they require a comparison between immediate, relatively certain results and future uncertain outcomes.

The propensity of managers to prefer current outcomes at the expense of future outcomes has received much attention in the accounting and finance literature (Bhojraj \& Libby, 2005; Chowdhury, 2011; Graham et al., 2005; Miller, 2002; Mizik, 2010; Mizik \& Jacobs, 2007; Narayanan, 1985; Tong \& Zhang, 2021). Such shortsighted behavior incompatible with long-term organizational goals has been called myopia (Merchant, 1990; Stein, 1989; Thaler et al., 1997). In the literature to date, it has been argued that too frequent performance evaluations, an overemphasis on earnings, and aggressive short-term performance-based incentives exacerbate myopic behavior (Merchant, 1990; Narayanan, 1985).

While the accounting and financial literature see myopia as a rational response to a too high frequency of reporting short-term profits, cognitive psychology implies that myopia may also be the result of a cognitive bias resulting from a person's limited ability to evaluate the distant future (Ardila et al., 1991; Bickel et al., 2011; Chi \& Fan, 1997; Simon et al., 2002; Tversky \& Kahneman, 1974). This research provides extensive evidence of distorted time cognition. It shows that people have a strong preference for sooner outcomes over shortly delayed ones (delay aversion), but that they make little distinction between two outcomes that are both delayed (Dasgupta \& Maskin, 2005; Green \& Myerson, 2004; Green et al., 1997). For example, if a receipt of $\$ 100$ is delayed for a year, most people would be willing to accept a much smaller amount of money if they received it immediately. However, people reverse their preference if a receipt of $\$ 100$ is delayed from year ten to year eleven, as they perceive almost no difference in the value of money. In other words, people consider the time value of money in the near future but are less sensitive when alternative outcomes are expected in the distant future. A similar pattern is found for certain and probable outcomes. People are willing to accept a much smaller certain outcome over a larger probable one (risk aversion), while they are unlikely to prefer a more probable smaller outcome over a less probable larger one if both are just probable. Delay and risk aversion are manifestations of how individuals discount delayed and risky choices. Behavioral research has found that our discounting differs significantly from the principles of exponential discounting, in theory expected of rational agents, (Samuelson, 1937) and can be better described by a hyperbolic discounting function (Green \& Myerson, 1996; Green et al., 1997; Prelec \& Loewenstein, 1991; Rachlin et al., 1991). Moreover, delay and risk aversion are believed to be based on the same underlying discounting processes, and this idea offers a potentially unifying theory to various phenomena in applied contexts. One of these, we argue, is myopic behavior. ${ }^{1}$

\footnotetext{
1 Another is investors' myopic loss aversion proposed by Benartzi \& Thaler (1995) which is defined as a combination of greater sensitivity to losses than to gains and short evaluation periods of portfolios that makes investors require an abnormally high premium on equity investments.
} 
From a management accounting perspective, it is not only important to understand the biases to which decision-makers are prone but also which control mechanisms can effectively mitigate them. Although managers are formally trained to maximize firm value and are supported by financial and accounting expertise, the degree of subjectivity in assessing outcomes in the distant future is high and leaves considerable scope for personal preferences and emotional reactions (Jermias, 2006; Kahneman \& Tversky, 1982). In other words, if managers (and people who support them) are prone to delay and risk aversion, that might profoundly impact how conservatively they predict future cash-flows, what probabilities they ascribe to them, and how they value the alternatives.

This paper explores whether process accountability can mitigate delay and risk aversion that leads to myopic decision making. Accountability refers to holding decision-makers accountable for their decisions and making them report to an authority (Edwards \& Hulme, 1996; Fox \& Brown, 1998). Process accountability means that decision-makers must explain and justify their decisions, while outcome accountability makes decision-makers accountable for the results of their decisions (De Langhe et al., 2011; Lerner \& Tetlock, 1999). Management control systems combine both; however, the emphasis different organizations place on one or the other varies. While the evidence about the effects of outcome accountability on decision making is extensive (e.g. Clearfield, 2005; Gigler et al., 2014; Graham et al., 2005; Kraft et al., 2018; Merchant, 1990; Narayanan, 1985, to name a few), the evidence on process accountability is limited (e.g. Chang et al., 2013; Dalla Via et al., 2019; Jermias, 2006; Lukas et al., 2019a, 2019b). Even more limited is the evidence on whether process accountability can attenuate cognitive biases (Bartlett et al., 2014; Libby et al., 2004).

In developing our hypotheses about what could attenuate delay and risk aversion, we have relied on Lerner and Tetlock's (1999) accountability theory, according to which individuals have a natural tendency to conform to expectations and appear rational if they are observed. This benefits their long-term social status, even if it is not associated with direct monetary outcomes (Ličen et al., 2016). However, people do not easily recognize their hard-wire biases, and we argue that accountability alone cannot make them realize their biases; it might even exacerbate them (Lerner $\&$ Tetlock, 1999). We hypothesize that accountability diminishes biases only if coupled with the information that leads individuals to recognize their excessive delay and risk aversion. Such information used as a nudge is not uncommon in practice. For example, when making important decisions, procedures may be set up that direct the managers' attention to certain important information, such as whether the current project meets the required rate of return, or the impacts of the current project on environment, etc. This study examines whether combining process accountability with reminding decision-makers of their subjective interest rates can effectively mitigate delay and risk aversion in managerial decision making.

We conducted an experiment that contains a within-subject and a between-subject factor. The participants were asked to choose among alternative outcomes in a series of delay and probability discounting tasks. In the first round, the participants completed the tasks with no accountability and then repeated them in the accountability condition (a within-subjects factor); that is, they were asked to justify their choice 
in writing (Bartlett et al., 2014; Dalla Via et al., 2019; Libby et al., 2004; Lukas et al., 2019a; Vieider, 2009). Half of the participants completed the second round of choices with a cue, and the other half completed it without the cue about what their subjective discount rates in the first round were (a between-subjects factor). Such design allowed us to measure the consistency of the participants' subjective discount rates over time and risk levels on an individual level and compare it between subjects. The experiment was tested online on a sample of $118 \mathrm{~s}$ and third-year students in accounting, management and finance programs from the University of Ljubljana.

Our results show that accountability coupled with the information on subjective discount rates leads to less myopic decision making as the participants could reduce their delay and risk aversion. We also find that under accountability without a cue, the participants were unable to recognize their excessive subjective discount rates suggesting that accountability in which decision-makers are prompted to think "harder" is not effective if no information is provided that would make them realize the bias.

The contribution of this study is the following. Biases in discounting affect every risky and long-term decision, which management accountants need to be more aware of. While prior accounting studies find justification pressure effective in certain circumstances, ${ }^{2}$ we show that justification pressure alone is ineffective for biases as persistent as excessive delay and risk aversion. However, when complemented by information that helps individuals realize them, it becomes more successful. In the absence of such a cue, justification pressure leads the participants to provide a self-serving account of the initially chosen alternative, as evident from our participants' responses. These findings contribute to a small body of research in accounting on the impact of process accountability on cognitive biases (Bartlett et al., 2014; Libby et al., 2004) and to previous research on risk aversion (Pahlke et al., 2015; Trautmann et al., 2008; Vieider, 2009; Weigold \& Schlenker, 1991). It sheds light on why prior studies found inconsistent results. It also contributes to the studies on accountability in management accounting, which compare the impact of outcome and process accountability on decision processing (Chang et al., 2013; Dalla Via et al., 2019).

The remaining part of the paper is structured as follows: Sect. 2 provides the theoretical background to delay and risk aversion, and accountability and develops the hypotheses. Section 3 focuses on the research method and the design of the experiment. Section 4 presents the results of the analysis. Section 5 discusses the results, outlines some limitations of the study, and concludes with the implications in Sect. 6.

\footnotetext{
${ }^{2}$ Prior studies presented evidence of the positive effect of justification pressure in the context of auditing (Ashton, 1992; DeZoort et al., 2006; Kennedy, 1993, 1995; Kim \& Trotman, 2015; Messier et al., 2014).
} 


\section{Theoretical background and hypotheses development}

\subsection{Risk and delay aversion as manifestations of hyperbolic discounting}

Delay and risk aversion lead to myopic behavior, and this is why it is reasonable to investigate the two biases together. Behavioral research of delay and risk aversion has led to the discovery of a discounting pattern that is considerably different from what the normative economic theory suggests (Frederick et al., 2002). The latter assumes that when deciding between an outcome now and one in the future, rational decision-makers translate future outcome to present value by discounting it in line with the exponential discounting function (Samuelson, 1937). The further away an outcome is, the more it gets discounted with a time-consistent discount rate. However, behavioral research provides strong evidence that people, in fact, discount differently: they strongly prefer an immediate smaller outcome to a shortly delayed larger one but reverse their preference when both outcomes are to be received in the future (Ainslie, 1975; Ainslie \& Herrnstein, 1981; Dasgupta \& Maskin, 2005; Green \& Myerson, 2004; Green et al., 1997; Rachlin \& Green, 1972). They use extremely high discount rates for the near future and declining discount rates for the distant future (Radu et al., 2011). Researchers describe such a reward valuation with the hyperbolic discounting function (Ainslie, 1975; Laibson, 1997).

Future outcomes are inherently risky. Kahneman and Tversky (1979) documented that individuals prefer smaller and certain outcomes over larger and riskier ones, but they reverse their preference when both alternatives are uncertain. A greater benefit of a smaller certain outcome over a larger riskier one is reflected in high required returns for risky outcomes. However, sensitivity to the same difference in probability decreases significantly when both options are probable because individuals' subjective discount rates are flatter at lower probabilities. Several studies suggest that probability discounting has a similar hyperbolic curve to delay discounting and that the two processes are closely related (Baucells \& Heukamp, 2012; Green et al., 1999; Halevy, 2008; Lopez-Guzman et al., 2018; Luckman et al., 2017; Rachlin et al., 1991). This notion is based on Rotter's observation (1954) that longer delays respond to lower probabilities of outcomes in real life.

\subsection{The effect of accountability on cognitive biases}

In this section, we theorize whether these biases could be mitigated by imposing accountability on decision making. In developing our hypotheses, we draw on Lerner's and Tetlock's (1999) accountability theory. One of its main arguments is that people have a natural tendency to conform to the expectations of those to whom they are accountable (Cialdini et al., 1976; Klimoski \& Inks, 1990; Lukas 
et al., 2019a; Quinn \& Schlenker, 2002; Tetlock, 1983, 1985; Tetlock et al., 1989). They associate conformance with long-term benefits, such as improving their social status and developing advantageous long-term relationships with supervisors. Individuals deeply care how others see them, even if no direct and immediate material consequences follow. ${ }^{3}$

Ličen et al., $(2016,2019)$ showed that not only supervisors' instructions but mere transparency and identifiability of results affect cognitive control, ${ }^{4}$ attention, conflict resolution and task processing and improve task performance. Efforts to meet the supervisors' expectations were also observed, even when these expectations were unknown, in the form of a more significant effort and a more thorough search for information about different alternatives (Huber \& Seiser, 2001; Huber et al., 2009; Lion \& Meertens, 2001; Tetlock, 1983; Tetlock \& Kim, 1987). However, in this case, the greater effort did not lead to a change in the agents' preferences, but on the contrary, to a more vigorous justification of the originally chosen alternative (Huber et al., 2009).

Libby et al. (2004) examined the effect of process accountability on the so-called common measure bias (that is, an overwhelming reliance on financial measures in a Balanced Scorecard, BSC). They observed whether accountability makes participants collect and rely on more information (cues) about subsidiary performance. They found that the requirement to justify the decision in writing led the participants to increase their reliance on the unique performance metrics in a BSC, which tended to be ignored. The authors attributed their findings to justification pressure inducing more cognitive effort. Bartlett et al. (2014) also examined the reliance on performance metrics in the context of BSC and found that the requirement to justify the decision in writing was an effective intervention that increased reliance on all BSC metrics. However, processing complex cues led the participants to increase rather than decrease the judgment bias. The authors attributed the finding to the fact that their BSC example was more complex and more reflective of real-world practices than the one in Libby et al. (2004). In a case where the "correct" solution is not apparent to a decision-maker, accountability increases utilization of cues and selfawareness of judgmental processes; however, if the decision-maker is not aware of bias, the search for more cues may amplify biased decision-making (Lerner \& Tetlock, 1999).

The question of whether individuals conform to supervisors' expectations is especially interesting when it comes to studying hard-wired time and risk preferences. Neurobiologists suggest that time and risk preferences are, in fact, a result of longterm survival choices. They cannot be attributed to too little cognitive effort as they are evolutionarily underpinned (Glimcher et al., 2005, 2007; Pessoa, 2008; Shiv

\footnotetext{
${ }^{3}$ Numerous examples of individuals' striving towards favorable evaluations of others (without any material consequences) are also provided by the impression management literature (Leary and Kowalski, 1990).

${ }^{4}$ Cognitive control (or executive function) is the human ability to regulate thoughts and actions in pursuit of goals (Botvinick et al., 2001; Braver, 2012; Braver et al., 2007). It requires complex coordination between the prefrontal cortex and the dorsal anterior cingulate cortex, the conflict-controlling region of the brain that inhibits spontaneous responses when not in accordance with goals.
} 
et al., 2005). In line with this view, accountability that urges people to think harder will be less effective in reducing deeply persistent behavior patterns. De Hoog and Van der Wittenboer (1986) found no effect of justification pressure on risk-taking, neither on the number of attributes used in the decision process nor on the choice of a risky versus a non-risky alternative. However, if supervisors' expectations are unknown to decision-makers, accountability might even have a counterproductive effect. Curley et al. (1986) reported that fear of a negative performance evaluation increased participants' ambiguity aversion because avoiding ambiguous decisions is believed to be more justifiable to others than adopting them. Trautmann et al. (2008) showed that by removing this fear, ambiguity aversion disappeared. Four studies suggested that accountability in various forms accentuated existing risk attitudes, making risk-averters more risk-averse and risk-seekers more risk-seeking (Baltussen et al., 2010; Jermias, 2006; Pahlke et al., 2015; Weigold \& Schlenker, 1991).

Only one study found that justification pressure made individuals reduce loss aversion (Vieider, 2009). The author attributed the finding to the activation of more cognitive effort under justification pressure and the recognition of the bias in the desire to be favorably evaluated by supervisors. His explanation draws on the dualprocess view (Ainslie \& Haslam, 1992; De Martino et al., 2006; Gonzalez et al., 2005; Kahneman, 2003; McClure et al., 2004), according to which the preference for immediate and certain outcomes is a result of the reliance on the affective system rather than on the more effortful cognitive system. ${ }^{5}$ This view implies that if accountability induces individuals to think harder, or if reformulation of the problem makes the bias more obvious, they are able to make more rational decisions (Loewenstein et al., 2008; Thaler \& Sunstein, 2003, 2008).

Within the theoretical framework of agency theory and under the assumption that agents are risk-neutral and rational, Lukas et al. (2019a) found that justification pressure to explain losses induces psychological costs that lead to risk aversion and suboptimal investment decisions for the principal. Lukas et al. (2019a) also pointed at the conformance problem that might elicit the opposite of what was intended.

One explanation for the conflicting findings of accountability on risk aversion could be that prior studies analyzed different types of decisions, used various manipulations of accountability (mere observation of others, evaluations of others, justification pressure, responsibility for others, explaining to vs. convincing supervisors), had different assumptions about agents' risk inclinations and, most importantly, that participants had different views on what would be the normatively correct answers. Lerner and Tetlock (1999) suggest that the effect of accountability depends on various moderators, including the cause of a bias, the type of accountability, the knowledge of supervisors' expectations and formal rules. They conclude that accountability attenuates bias only (1) when it makes individuals gain awareness of their

\footnotetext{
5 Neurobiologists oppose the dual process view suggesting that different parts of the brain are responsible for decisions. As expressed by Pessoa (2008, p. 148), "complex cognitive-emotional behaviors are based on dynamic coalitions of networks of brain areas, none of which should be conceptualized as specifically affective or cognitive'. According to this view risk-averse behavior is more a question of longterm survival than a single financial decision.
} 
cognitive processes and (2) when they actually understand what the supervisors' expectations are.

Based on the view that time and risk preferences are hard-wired and following prior arguments that conforming to expectations under accountability may not undo the bias, when people do not realize they are biased, we suggest that the same will apply to the current context. Delaying an outcome or evaluating its probability is a compelling cognitive problem, and the subjective discount rates, implicit in choices, are not apparent to decision-makers. Accountability could be effective only if individuals obtained some information indicating their decision-inconsistencies, i.e., that they use extremely high discount rates which fall with remoteness/increasing risk of outcomes. With these cues, they are able to see at what cost they favor immediate and certain outcomes over delayed and risky ones. This leads us to predict that only accountability with a cue about subjective discount rates will reduce high discount rates for probable outcomes compared to certain ones and for delayed outcomes compared to immediate ones because it will help individuals realize the excessive discount rates. Therefore, we propose to test the following hypotheses:

H1: Process accountability coupled with a cue about subjective discount rates attenuates delay aversion.

H2: Process accountability coupled with a cue about subjective discount rates attenuates risk aversion.

\section{Research method}

\subsection{Participants}

We conducted an online experiment with 125 students majoring in accounting, management or finance at the European University. Seven participants (5.6\%) were eliminated from the analysis due to technical issues with the E-Prime Go on some computers during the experiment. In the analysis reported below, 118 participants were considered (74 females, age $M=21.64, S D=2.42$, range $=20-35$ years) with an average 2.9 years of work experience $(S D=2.51$, range $=0-15$ years $)$. The participants were encouraged to participate in the study with a course credit. At the beginning of the experimental task, they were informed that the computer would randomly select some participants to receive the actual outcome based on one of the decisions made during the experiment (as in Pahlke et al., 2012; Vieider, 2011). In the case of the temporal choice, the outcome would be paid in the chosen time; that is, if a participant chose a larger outcome with a delayed payment over a smaller immediate outcome, their payment was delayed. Even though not every participant was compensated, the possibility to get an outcome of up to EUR 40 appeared to be sufficient to motivate them to participate. In total, 16 students were selected based on the random draw and paid a total amount of EUR 480 or an average of EUR 30 per participant. The longest time participants have to wait for the earned reward is 1 year.

Before starting the online experiment, all participants were informed that their participation was voluntary and that they were free to withdraw from the experiment 
Table 1 Design of the experimental task

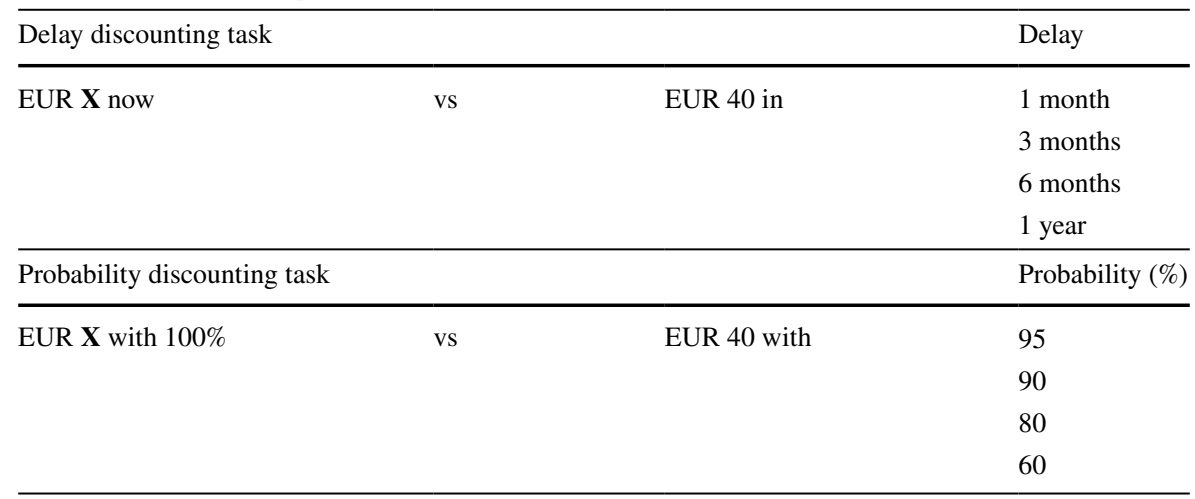

at any time without consequences. By clicking on the link, they gave their consent to participate. The study and procedures were approved by the Ethics Research Committee of the University of Ljubljana, where the experiment was conducted.

\subsection{Task}

Studies investigating delay discounting involve a series of choices between a smaller reward available sooner and a larger reward available later. Similarly, the probability discounting studies contain a series of choices between a smaller certain reward and a larger riskier reward. To measure individuals' delay and risk inclination, we used a choice task with a discount titration (e.g., Green et al., 2004; Mazur, 1984, 1985, 1988; Mazur \& Coe, 1987; Mazur et al., 1985). The titration procedure incrementally adjusts the amount of reward, its delay or probability until the subject becomes indifferent between the two presented options. By that, the researcher can establish the subjects' indifference points (Vanderveldt et al., 2016). For illustration, in the series of choices, the participants had to choose between the immediate and the delayed reward being provided at a fixed point in time (after 1, 3 and 6 months, and 1 year). The initial immediate reward was EUR 40 and was systematically titrated by EUR 2 in each trial. The delayed reward remained the same in all trials (EUR 40); namely, in the first trial, the participants had to choose between EUR 40 immediately versus EUR 40 after 1 month, in the second trial between EUR 38 immediately versus EUR 40 after 1 month, and so on. At a certain point, in which the amount of the immediate reward was diminished to an unacceptable level for the participant, they chose the delayed reward. The amount of the immediate reward was defined as the participant's indifference point at a 1-month delay. Once the indifference point was determined, the first series of trials were completed. Then, we tested the same set of choices, but with a delay of 3 and 6 months and 1 year (see Table 1 for illustration).

A similar procedure was applied for the probability discounting task. The participants had to choose between a certain reward and a risky reward in the series of choices. The probabilities of the risky reward were $95 \%, 90 \%, 80 \%$ and $60 \%$. 
The risky reward remained fixed in all trials at EUR 40, whereas the certain reward gradually decreased from the initial EUR 40 by EUR 2 in each trial (i.e., in the first trial, the participants had to choose between EUR 40 with a $100 \%$ probability versus EUR 40 with a $95 \%$ probability, in the second trial between EUR 38 with a $100 \%$ probability versus EUR 40 with a $95 \%$ probability, and so on until the indifference point was reached; see Table 1). Based on the participants' choices in all series, we calculated their subjective discount rates (discount factor $k$; a further explanation is provided in the Data analysis section).

The delay and probability discounting tasks were programmed in the E-prime 3.0 software (Psychology Software Tools, 2016). For the online execution of the experiment, we used the E-prime Go 1.0 program (Psychology Software Tools, 2020). During the online experiment participants were monitored using Zoom. We analyzed the data in R 4.0.3 (R Core Team, 2020).

\subsection{Procedure and accountability manipulation}

We manipulated the non-accountability condition by telling the participants that their responses would not be identifiable. We manipulated the accountability condition in two ways-with and without a cue. In the accountability condition without a cue, participants were asked to write down a clear justification of their choice to the supervisor of the experiment for each task. In the accountability condition with a cue, in addition to the requirement to justify their choice, the participants received the information on their subjective discount rates in the non-accountability condition, which was computed by a computer in real-time. For example, if they chose EUR 26 immediately versus EUR 40 in a month, their subjective discount rate was $53.8 \%$. This information served to help participants realize their (otherwise implicit) discount rates, and to appear rational in their justifications to supervisors should make them decrease excessive rates.

The participants first performed the task in the non-accountability condition. Then $63(53.4 \%)$ of them completed the task in the accountability condition without a cue and $55(46.6 \%)$ in the accountability condition with a cue. We did not randomize the order of non-accountability and accountability conditions, because first, it would not be possible to design the accountability condition with a cue without the information on subjective discount rates; and second, in tasks measuring individuals' risk and temporal preferences, the learning effect does not apply, and third, if one has to justify the decision in the first round of the experiment, it would be impossible to undo this effect in the second round in the non-accountability condition.

The research was conducted in five online Zoom sessions. Each session had 25 participants and lasted approximately $30 \mathrm{~min}$. The participants were invigilated with a camera during the experiment and could call on the support of the researchers if they had any questions. The exit questionnaire measured age, gender and years of work experience. 


\subsection{Data analysis}

The indifference points were derived from the choices in all delay and risk trials. Using the indifference points, we were able to determine individuals' subjective discount rate (discount factor $k$ ) for every choice set based on Eq. 1 (Mazur, 1987) and Eq. 2 (Rachlin et al., 1991):

$$
\begin{gathered}
V=\frac{A}{(1+k D)} \\
V=\frac{A}{(1+k \theta)}, \theta=\frac{1-p}{p}
\end{gathered}
$$

where $V$ is the subjective (discounted) value (i.e., indifference point) of the delayed or risky amount $A, D$ is the delay in months (1,3, 6, and 12 months), $\theta$ is the odds of not receiving the risky reward, and $p$ is the probability of receiving it. ${ }^{6}$ The subjective discount rate for each individual is computed based on Eqs. 1 and 2 that are solved for $k$. The discount rate describes an individual's delay and risk aversion, which underlie a myopic tendency. A lower indifference point results in a higher subjective discount rate and reflects a steeper delay or probability discounting (i.e., greater discounting of future or riskier options) and a stronger delay or risk aversion.

Because discount rates range from 0 to $4000 \%, 7,8$ we used the log transformation method to normalize skewed values. By normalizing the discount rates, the validity of the associated statistical analyses increases (Feng et al., 2014). The normalized discount rates are analyzed for each task separately, using the repeated measures analysis of variance (ANOVA) with the delay ( 1 vs. 3 vs. 6 vs. 12 months) or probability (5\% vs. $10 \%$ vs. $20 \%$ vs. $40 \%$ ) and the accountability condition (non-accountability vs. accountability without a cue, nonaccountability vs. accountability with a cue) as within-subjects factors and cue (accountability without a cue vs accountability with a cue) as between-subjects factor. The discount rates for various intervals are calculated on a monthly basis

\footnotetext{
${ }^{6}$ For the probability discounting choices, $p$ (probability) equals $.95, .90, .80$ and .60 , which corresponds to the values of $\theta$ obtained in Eq. 2 as $.053, .111, .25$ and .667 .

7 The discount rates are not to be taken at face value. They are induced by the concrete experimental design rather than being a result of the outrageous delay aversion by our participants. For example, the participants had to decide between an outcome of EUR 40 delayed by one month and the lowest value they would accept if paid out immediately. If they indicated the lowest value of EUR 38, we calculated the indifference point as EUR 39 (the midpoint between EUR 40 and EUR 38) and the discount rate of $2.6 \%$ on a monthly level. If, on the other hand, individuals were unwilling to accept a delayed outcome at any value, they indicated that with zero, which resulted in an indifference point of 1 (for the sake of calculation) and a discount rate on an annual basis of $4,000 \%$. The distribution of such discount rates resulted in the extremely high mean values.

${ }^{8}$ Subjective discount rates in the experiment are similar as those in previous studies. Thaler (1981) also asked participants what amount of money would make them indifferent to receiving $\$ 15$ now in one month/one year/ten years. The median responses imply an average (annual) discount rate of $345 \%$ over a one-month horizon, $120 \%$ over a one-year horizon, and $19 \%$ over a ten-year horizon. Other studies report similar patterns (Benzion et al., 1989; Chapman, 1996; Pender, 1996; Redelmeier and Heller, 1993).
} 


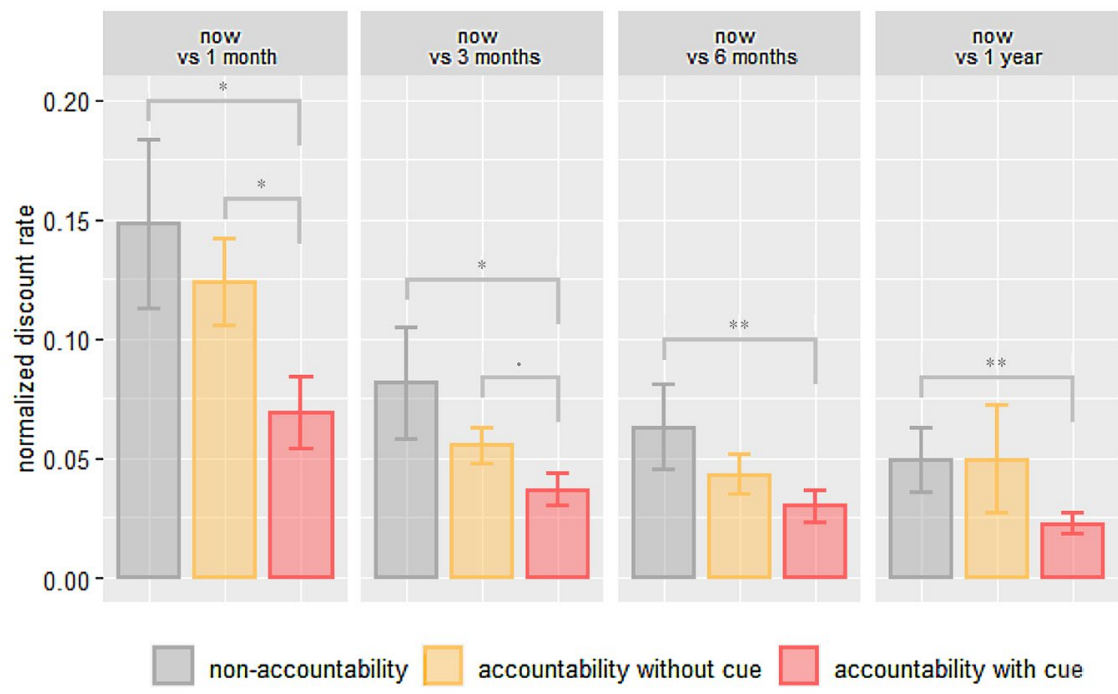

Note: $. p<0.1, * p<.05 ; * * p<.01$. The delayed rewards are paid out at indicated times after the immediate reward, measured in months. A higher normalized discount rate reflects steeper delay discounting.

Fig. 1 Normalized discount rates in the delay discounting tasks

Table 2 Descriptive statistics for the delay discounting task and the results of the paired sample $t$-test of non-accountability and accountability without a cue for the normalized discount rates

\begin{tabular}{|c|c|c|c|c|c|c|c|c|}
\hline \multirow{2}{*}{$\begin{array}{l}N=63 \\
\text { Task }\end{array}$} & \multicolumn{3}{|c|}{ Non-accountability } & \multicolumn{3}{|c|}{ Accountability without a cue } & \multicolumn{2}{|l|}{$\mathrm{t}$ test } \\
\hline & $M$ & $S D$ & t test & $M$ & $S D$ & t test & $t$ & $p$ \\
\hline Now vs. 1 month & 0.166 & 0.49 & $t=1.75$ & 0.124 & 0.14 & $t=1.43$ & 0.76 & 0.448 \\
\hline Now vs. 3 months & 0.104 & 0.34 & $t=2.62$ & 0.055 & 0.06 & $t=3.33$ & 1.16 & 0.249 \\
\hline Now vs. 6 months & 0.076 & 0.25 & $t=3.02$ & 0.043 & 0.06 & $t=1.72$ & 0.99 & 0.327 \\
\hline Now vs. 1 year & 0.061 & 0.19 & $t=0.50$ & 0.049 & 0.18 & $t=-0.99$ & 0.34 & 0.734 \\
\hline
\end{tabular}

Paired sample t-test comparing the normalized discount rates in the non-accountability versus the accountability condition without a cue is presented in the last column.

to be comparable and then log-transformed to get a normalized value. For the interpretation, they need to be exponentially transformed (inverse of log transformation). In cases where the assumption of sphericity is violated, which indicates that the variance of the differences between all combinations of related groups is not equal, the degrees of freedom are adjusted according to the Greenhouse-Geisser correction method (Field, 2009). 
Table 3 Descriptive statistics for the delay discounting task and the results of the paired sample $t$-test of non-accountability and accountability with a cue for the normalized discount rates

\begin{tabular}{|c|c|c|c|c|c|c|c|c|}
\hline \multirow{2}{*}{$\begin{array}{l}N=55 \\
\text { Task }\end{array}$} & \multicolumn{3}{|c|}{ Non-accountability } & \multicolumn{3}{|c|}{ Accountability with a cue } & \multicolumn{2}{|l|}{ t test } \\
\hline & $M$ & $S D$ & t test & $M$ & $S D$ & t test & $t$ & $p$ \\
\hline Now vs. 1 month & 0.127 & 0.20 & $t=2.51$ & 0.069 & 0.11 & $t=1.44$ & 2.31 & 0.025 \\
\hline Now vs. 3 months & 0.056 & 0.08 & $t=2.79$ & 0.037 & 0.05 & $t=0.66$ & 2.17 & 0.034 \\
\hline Now vs. 6 months & 0.047 & 0.07 & $t=2.54$ & 0.030 & 0.05 & $t=0.59$ & 2.74 & 0.008 \\
\hline Now vs. 1 year & 0.036 & 0.06 & $t=1.53$ & 0.022 & 0.03 & $t=-1.51$ & 2.67 & 0.010 \\
\hline
\end{tabular}

Significant differences appear in bold. The paired sample t-test comparing the normalized discount rates in the non-accountability versus the accountability condition with a cue is presented in the last column.

Table 4 The ANOVA analysis for delay discounting task

\begin{tabular}{|c|c|c|c|}
\hline Subjective discount rate & $F$ & $p$ & sig \\
\hline \multicolumn{4}{|l|}{ Model 1 (within-subjects, $N=63$ ) } \\
\hline Intercept & 16.21 & $<0.001$ & $* * *$ \\
\hline Delay & 0.43 & $\mathbf{0 . 0 0 1}$ & $* *$ \\
\hline Accountability (non-account. vs. account. without a cue) & 0.78 & 0.380 & \\
\hline Delay $\times$ accountability & 0.66 & 0.577 & \\
\hline \multicolumn{4}{|l|}{ Model 2 (within-subjects, $N=55$ ) } \\
\hline Intercept & 34.22 & $<0.001$ & $* * *$ \\
\hline Delay & 0.42 & $<0.001$ & $* * *$ \\
\hline Accountability (non-account. vs. account. with a cue) & 13.01 & $<0.001$ & $* * *$ \\
\hline Delay $\times$ accountability & 2.35 & $\mathbf{0 . 0 7 5}$ & \\
\hline \multicolumn{4}{|l|}{ Model 3 (between-subjects, $N=118$ ) } \\
\hline Intercept & 70.02 & $<0.001$ & $* * *$ \\
\hline Delay & 0.53 & $<0.001$ & $* * *$ \\
\hline Accountability (with vs. without a cue) & 4.92 & 0.028 & $*$ \\
\hline Delay $\times$ accountability & 1.41 & 0.241 & \\
\hline
\end{tabular}

Significant and marginally significant differences appear in bold $p<0.1, * p<0.05, * * p<0.01, * * * p<0.001$

\section{Results}

\subsection{The impact of accountability on delay aversion}

Figure 1, Tables 2 and 3 present the normalized discount rates used to discount delayed rewards in the set of trials with choices between an immediate and a delayed reward of 1, 3, 6 and 12 months. The results of the paired sample t-test reveal that high normalized discount rates were not significantly different under the accountability without a cue condition (see Fig. 1 and Table 2, t-test column) 
and were successfully decreased when accountability was coupled with a cue (see Fig. 1 and Table 3, t-test column).

The within-subjects ANOVA analysis of the effect of accountability without a cue on the normalized discount rate for the delay discounting task shows a significant main effect of the delay, $F(3,186)=0.43, p=0.001$, that reflects the decrease in the discount rate with the increasing time delay. On the contrary, main effect of the accountability condition, $F(1,62)=0.78, p=0.380$, and delay $\times$ accountability interaction, $F(3,186)=0.66, p=0.577$, is found non-significant reflecting similarly high and inconsistent discount rates in both manipulated conditions (see Fig. 1 and Table 4, Model 1). The results suggest that accountability without a cue is not effective in reducing delay aversion.

The within-subject ANOVA of the effect of accountability with a cue on the normalized discount rate for the delay discounting task comparing the conditions of non-accountability and accountability with a cue shows a significant main effect of the delay, $F(3,162)=0.42, p<0.001$, revealing a decline in a discount rate with an increasing delay. We also observe a significant main effect of accountability condition, $F(1,54)=13.01, p<0.001$, which reflects that lower discount rates are used in the accountability with a cue condition, and a marginally significant delay $\times$ accountability interaction, $F(3,162)=2.35, p=0.075$, indicating the use of more consistent discount rates under increasing delay in the accountability with a cue compared to the non-accountability condition (see Fig. 1 and Table 4, Model 2).

The between-subjects ANOVA of the effect of the cue on the normalized discount rate for the delay discounting task shows a significant main effect of the delay, $F(3,348)=0.53, p<0.001$, the significant main effect of the cue, $F(1,116)=4.92$, $p=0.028$, which reflects that lower discount rates are used in the accountability condition with a cue, but there is no significant delay $\times$ cue interaction, $F(3,348)=1.41$, $p=0.241$ (see Fig. 1 and Table 4, Model 3).

Overall, the results confirm $\mathrm{H} 1$ and show that imposing justification pressure coupled with a cue significantly attenuates delay aversion in terms of reducing excessive discount rates.

\subsection{The impact of accountability on probability discounting}

Figure 2, Tables 5 and 6 present the descriptive statistics for the normalized discount rates obtained in the probability discounting task that are calculated based on the indifference point by using Eq. 2 and then log-transformed. The results of the paired sample $t$-test confirm that the participants' mean discount rates are similarly high for almost all choices in the non-accountability condition compared to accountability without a cue condition (see Fig. 2 and Table 5, t-test column) and significantly lower for three out of four choices in the accountability with a cue in comparison to the non-accountability condition (see Fig. 2 and Table 6, t-test column), suggesting that accountability with a cue can mitigate risk aversion. In a within-subjects analysis, results show significantly (and marginally significantly) higher discount rates when comparing certain and probable options (Tables 5, 6). 


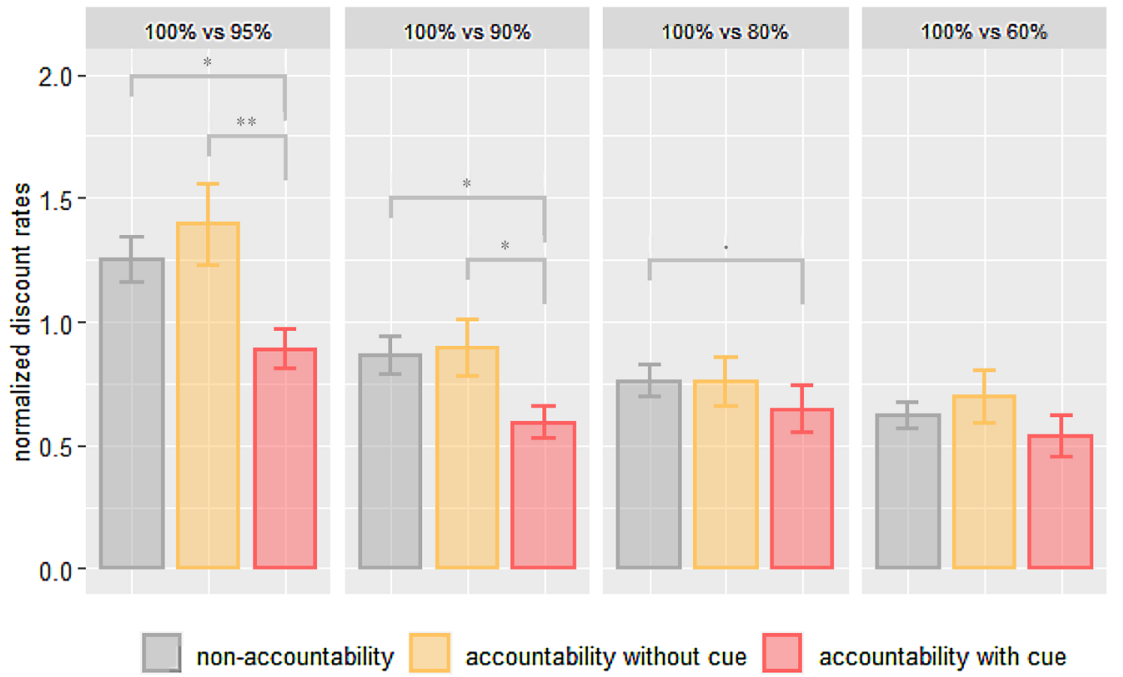

Note: $. p<0.1, * p<.05 ; * * p<.01$. The probability of less probable options decreases by the $5,10,20$ and 40 percentage points. A higher normalized discount rate reflects steeper probability discounting and stronger risk aversion.

Fig. 2 Normalized discount rates in the probability discounting tasks

Table 5 Descriptive statistics for the probability discounting task and the results of the paired sample $t$-test of non-accountability and accountability without a cue for the normalized discount rates

\begin{tabular}{|c|c|c|c|c|c|c|c|c|c|}
\hline \multicolumn{2}{|l|}{$N=63$} & \multicolumn{3}{|c|}{ Non-accountability } & \multicolumn{3}{|c|}{$\begin{array}{l}\text { Accountability without } \\
\text { a cue }\end{array}$} & \multicolumn{2}{|l|}{ t-test } \\
\hline Task & $\Delta$ Risk & $M$ & $S D$ & $t$-test & $M$ & $S D$ & $t$-test & $t$ & $p$ \\
\hline $100 \%$ vs. $95 \%$ & 5 p.p & 1.396 & 1.17 & $t=3.32$ & 1.395 & 1.31 & $t=3.12$ & 0.004 & 0.996 \\
\hline $100 \%$ vs. $90 \%$ & 10 p.p & 0.938 & 0.96 & $t=3.44$ & 0.894 & 0.93 & $t=3.87$ & 0.50 & 0.616 \\
\hline $100 \%$ vs. $80 \%$ & 20 p.p & 0.784 & 0.68 & $t=1.46$ & 0.757 & 0.78 & $t=3.14$ & 0.39 & 0.694 \\
\hline $100 \%$ vs. $60 \%$ & 40 p.p & 0.664 & 0.64 & $t=1.79$ & 0.699 & 0.85 & $t=2.60$ & -0.30 & 0.765 \\
\hline
\end{tabular}

The paired sample t-test comparing the normalized discount rates in the non-accountability versus the accountability condition without a cue is presented in the last column

The within-subjects ANOVA analysis of the effect of accountability without a cue on the normalized discount rate for the probability discounting task for the choices between certain and risky rewards shows a significant main effect of risk, $F(3,186)=0.53, p<0.001$, indicating a decrease in the discount factor with increasing risk, but no significant main effect of the accountability condition, 
Table 6 Descriptive statistics for the probability discounting task and the results of the paired sample $t$-test of non-accountability and accountability with a cue for the normalized discount rates

\begin{tabular}{|c|c|c|c|c|c|c|c|c|c|}
\hline \multicolumn{2}{|l|}{$N=55$} & \multicolumn{3}{|c|}{ Non-accountability } & \multicolumn{3}{|c|}{ Accountability with a cue } & \multicolumn{2}{|l|}{$\mathrm{t}$ test } \\
\hline Task & $\Delta$ Risk & $M$ & $S D$ & t test & $M$ & $S D$ & t test & $t$ & $p$ \\
\hline $100 \%$ vs. $95 \%$ & 5 p.p & 1.083 & 0.71 & $t=3.85$ & 0.890 & 0.58 & $t=1.73$ & 2.01 & 0.049 \\
\hline $100 \%$ vs. $90 \%$ & 10 p.p & 0.772 & 0.61 & $t=1.48$ & 0.593 & 0.48 & $t=-0.27$ & 2.39 & $\mathbf{0 . 0 2 0}$ \\
\hline $100 \%$ vs. $80 \%$ & 20 p.p & 0.733 & 0.73 & $t=2.97$ & 0.646 & 0.72 & $t=2.16$ & 1.91 & 0.061 \\
\hline $100 \%$ vs. $60 \%$ & 40 p.p & 0.569 & 0.57 & $t=2.68$ & 0.537 & 0.60 & $t=2.88$ & 0.85 & 0.397 \\
\hline
\end{tabular}

Significant and marginally significant differences appear in bold. The paired sample t-test comparing the normalized discount rates in the non-accountability versus the accountability condition with a cue is presented in the last column.

Table 7 The ANOVA analysis for probability discounting task

\begin{tabular}{|c|c|c|c|}
\hline Subjective discount rate & $F$ & $p$ & sig \\
\hline \multicolumn{4}{|l|}{ Model 4 (within-subjects, $N=63$ ) } \\
\hline Intercept & 104.70 & $<0.001$ & $* * *$ \\
\hline Risk & 0.53 & $<0.001$ & $* * *$ \\
\hline Accountability (non-account. vs. account. without a cue) & 0.02 & 0.902 & \\
\hline Risk $\times$ Accountability & 0.16 & 0.926 & \\
\hline \multicolumn{4}{|l|}{ Model 5 (within-subjects, $N=55$ ) } \\
\hline Intercept & 124.20 & $<0.001$ & $* * *$ \\
\hline Risk & 0.59 & $<0.001$ & $* * *$ \\
\hline Accountability (non-account. vs. account. with a cue) & 7.85 & 0.007 & $* *$ \\
\hline Risk $\times$ accountability & 1.66 & 0.177 & \\
\hline \multicolumn{4}{|l|}{ Model 6 (between-subjects, $N=118$ ) } \\
\hline Intercept & 163.81 & $<0.001$ & $* * *$ \\
\hline Risk & 0.66 & $<0.001$ & $* * *$ \\
\hline Accountability (with vs. without a cue) & 4.63 & $\mathbf{0 . 0 3 3}$ & * \\
\hline Risk $\times$ accountability & 0.66 & $\mathbf{0 . 0 5 3}$ & \\
\hline
\end{tabular}

Significant and marginally significant differences appear in bold

$p<0.1, * p<0.05, * * p<0.01, * * * p<0.001$

$F(1,62)=0.02, p=0.902$, nor risk $\times$ accountability interaction, $F(3,186)=0.16$, $p=0.926$, indicating similar discount rates in both, accountability without a cue and the non-accountability condition (see Fig. 2 and Table 7, Model 4).

The within-subjects ANOVA of the effect of accountability with a cue on the normalized discount rate for the probability discounting task shows a significant main effect of risk $F(3,162)=0.59, p<0.001$, reflecting a decrease in the discount rate with increasing risk, a significant main effect of the accountability condition, $F(1,54)=7.85, p=0.007$, indicating the participants became less risk-averse under accountability with a cue, but no significant risk $\times$ accountability interaction, $F(1$, 
$162)=1.66, p=0.177$, which do not confirm the use of more consistent discount rates under accountability with a cue (see Fig. 2 and Table 7, Model 5).

The between-subjects ANOVA of the effect of the cue on the normalized discount rate for the probability discounting task shows a significant main effect of risk, $F(3,348)=0.66, p<0.001$, the significant main effect of the cue, $F(1,116)=4.63$, $p=0.033$, which shows that lower discount rates are used in the accountability condition if it is coupled with a cue, and also a marginally significant risk $\times$ cue interaction, $F(3,348)=0.66, p=0.053$, reflecting the use of slightly more consistent discount rates under accountability with a cue (see Table 7, Model 6).

Our findings reveal that accountability with a cue successfully reduces excessive risk aversion supporting $\mathrm{H} 2$. Overall, the results testing $\mathrm{H} 1$ and $\mathrm{H} 2$ show that accountability reduces the magnitude of both delay and risk aversion in the cue condition. In contrast, the same accountability reduces neither delay nor risk aversion in the no cue condition.

\subsection{The analysis of participants' responses under the accountability conditions}

In an attempt to substantiate our findings, we examined the participants' responses elicited in the accountability condition. The participants were asked to write down a clear justification of their choices to the supervisor and told that the responses could be traced back to them (see the Appendix for experimental instrument). Our manipulation was intended to have an ex-ante effect on decision processing rather than serve as evidence to test hypotheses. The instruction had to be sufficiently flexible to accommodate the accountability with a cue and without a cue. In other words, we did not try to elicit answers about how precisely the cue affected their choices as then our manipulation of accountability could not be the same across both conditions or would be too suggestive.

In the analysis of the responses, no participant in the accountability condition with a cue referred explicitly to their concrete discount rates that they had seen on the screen. However, more often than those without a cue, they justified their choices by referring to the required rates of returns or made comparisons to explicit interest rates. The participants without a cue justified them more generally-either as their personal inclination towards certainty and immediacy or in absolute amounts of outcomes. For example: "It is important to me to get the money as soon as possible.", "I would rather have something for certain, than lose everything.", "A bird in the hand is worth two in the bush."

Some quotes of the participants under accountability with a cue: "I don't need money now, so I can wait a year longer for higher returns (if we recalculate, this is a $5-6 \%$ return in one year).", "I prefer $100 \%$ probability over $60 \%$ probability, as risk makes me nervous.", "The $50 \%$ probability is a boundary between choosing yes and no. The $30 \%$ probability is too low for me. I am satisfied with a lower amount because the probability of a higher amount is already quite small, and it is no longer worth the risk."

In very few instances, we detected an explicit quote of re-evaluation of risks or explicit mention of the expected utility in the accountability with a cue condition: 
"I have re-evaluated the risks.", "I weigh the risk and the amount and the expected utility."

Some of the participants mentioned their personal circumstances that led them to the decision: "Given my life conditions, it means much more to me to get the money sooner than later. I can give up some money to get it sooner." However, such responses could not be distinguished between those who had a cue and those who did not. However, they highlight that individuals do not make financial decisions in a social vacuum and often consider them in combination with other essential life circumstances (Gigerenzer, 2007; Lerner \& Tetlock, 1999). This offers some support to the assumption that these biases are hard-wired and not easily undone.

Predominantly, it seems that our participants were justifying their innate aversion towards delay and risks and that those with a cue did it more often by explicitly referring to discount rates. Still, the variation in responses did not warrant a quantitative analysis to detect significant differences. As mentioned, this might be because we left the question too open to be able to elicit their more accurate responses as to how their choices compare to those from the non-accountability condition. Eliciting responses is, in general, seen as less reliable evidence in providing introspection into subconscious choices (e.g., Horgan \& Timmons, 2011) than factual evidence coming from experimental choices.

\section{Discussion}

As observed in many prior studies, our participants also required abnormally high discount rates to be willing to give up a certain and immediate outcome for a probable and delayed outcome in their baseline choices (in the non-accountability condition). We analyzed whether process accountability is able to attenuate their delay and risk aversion, one of the leading cognitive causes of myopia. Prior evidence about the effect of process accountability on risk aversion is mixed, and on delay aversion entirely lacking. Moreover, no previous study has simultaneously analyzed the impact of accountability on both biases suggested to have a common root cause (Rotter, 1954). In the development of our hypotheses as to what could attenuate these hard-wired preferences (Gigerenzer, 2007; Glimcher et al., 2005, 2007; Pessoa, 2008; Shiv et al., 2005), we hypothesize that although agents aspire to appear rational in the eyes of their supervisors (Lerner \& Tetlock, 1999), accountability cannot make them aware of the biases unless coupled with a cue.

To test the hypotheses, we designed the accountability condition in which we made participants aware of their subjective discount rates and compared their decisions to those in the non-accountability condition and in the accountability condition in which no such information was provided. For delay aversion, we find that the accountability with a cue significantly reduces excessive discount rates and affects choices between immediate and delayed outcomes. Our results also suggest that accountability contributes to using more consistent discount rates over time (marginally significant). We obtain qualitatively similar results for risk aversion. When a cue is absent, justification pressure is not powerful enough to affect participants' choices. 
Our findings on the effect of accountability on risk aversion contribute to the understanding of previous studies' contrasting results, which typically did not analyze accountability with a cue and reported that accountability only made their participants more ardently defend their original choices. The interpretation of our findings accords with De Langhe et al. (2011), who suggest that accountability can improve the quality of judgment in simple tasks, but not in complex tasks-a cue simplifies the decision as it makes individuals more aware of their excessive discount rates, which they assume are unlikely to be in line with supervisors' expectations. A question is whether a cue alone would be enough to mitigate the two biases. If individuals believe that their decision making will remain private and not monitored, they will not change their decisions. However, providing a cue assumes that one's behavior is observed, and this already counts as a form of accountability-visibility of results to supervisor (Lerner \& Tetlock, 1999). Given the ineffectiveness of justification pressure in our study, future research could design an experiment in which a cue with and without visibility of results would be investigated.

A concern related to the external validity of our study could be how relevant our experiment is for decision making in the organizational setting. Most managers are provided with training on the formal rules of exponential discounting (as a part of their Business, Commerce or Economics degree) or are well supported by accounting and finance professionals. By using second and third-year students in accounting, finance and management, we show that even people who understand the rules are prone to excessive delay and risk aversion. When it comes to decisions to commit considerable resources to long-term projects, there will always be room for subjective preferences that depend on how comfortable a particular decision-maker feels with these decisions. Moreover, managers do not make any decision about the future in which probabilities, future cash flows or their distribution would be known. They have to deal with unknown probabilities and estimated future cash flows, and that only introduces more complexity into decision making and exacerbates their aversion to risks and remote cash flows.

The finding that process accountability with a cue mitigates delay and risk aversion underlines the need to combine both types of accountability in management control systems to make process accountability offset the negative effects of outcome accountability on management's time and risk orientation (Graham et al., 2005; Kraft et al., 2018; Merchant, 1990; Narayanan, 1985; Thanassoulis, 2012). One of such cues could be to transparently present the supervisors' expectations about the required rates of return, even when they are difficult to estimate (for example, in closely held firms and for projects that are riskier than an average project in a firm). Another suggestion that could alleviate risk and delay aversion would be clear communication by the supervisors about the levels of risk tolerance an organization is prepared to accept. Often managers are held personally accountable for a project's failure although it is within the acceptable loss limits defined by the enterprise risk management. Such misalignment reinforces biases and fears. A third suggestion of our findings would be to remind decision-makers about their implied subjective discount rates to make them more patient.

We note that our findings have some limitations inherent in the experimental method. The experiment shows the use of very high discount rates, which are not 
realistic in real life. They are an artifact of the actual experimental design and should not be taken at face value. The experiment was methodologically designed based on several previous studies aimed at deriving the discounting function (Green et al., 2004; Mazur et al., 1985; Richards et al., 1997). We prepared the choices so that they would be realistic, attractive and relevant to our participants and would keep the payout within our budget. Had we changed the amounts, we might have obtained different discount rates. ${ }^{9}$ An experiment is relatively restrictive in the design and impedes picking up fine changes in the discount rate. What is important in an experiment is the sign and strength of the relationship between the independent and the dependent variables.

Another limitation may be that the participants perceived the choices as hypothetical since not all choices were paid out, and only 16 participants received a reward. Madden et al. (2003) compared discount rates in real money and hypothetical scenarios and reported similar discount rates regardless of the manipulation. Vieider (2009), for example, used no monetary incentives at all in his risk aversion experiment. Another concern may be the order of the conditions: participants made their decisions first under non-accountability and then under accountability. We argue that the learning effect is not an issue in these types of tasks, as they relate to preferences and not to performance. That is shown in the accountability condition without a cue that had no significant effect on choices in the second round of the experiment. Furthermore, after the experience of accountability, participants would not be able to reverse "harder" thinking in the non-accountability condition. We also acknowledge the limitation that in eliciting responses from the participants in the justification pressure condition, we did not design the instruction in such a way so that it could provide conclusive evidence to support our experimental findings. However, our hypotheses are rigorously tested, and even though a quantitative analysis of participants' responses is not feasible, we still believe that they are informative and support our interpretation of the results.

Last but not least, the experiment was conducted online. As is the case in a lab experiment, the number of participants per session was limited to the capacity of researchers to be able to monitor the activity of each participant. We did not experience any issues and believe that our results were not impacted in any way.

\section{Conclusion}

Delay and risk aversion have a profound effect on long-term business decisions. The study's contributions aim to highlight cognitive constraints on temporal and risky decision making, which are the two most important processes underlying the evaluation of long-term outcomes. We theorize and provide original evidence on the extent to which accountability can reduce such tendencies, and that is not by mere

\footnotetext{
${ }^{9}$ For example, if we designed a choice between EUR 40 immediately and EUR 39.50 in a month, this would still mean an annual discount rate of $15 \%$, whereas the participants would hardly see any sense in delaying 50 cents for a month.
} 
justification pressure but by providing a cue on subjective discount rates. It is crucial for academic and practicing management accountants to understand when and why decision-makers engage in myopic behavior, not only because of their self-interest but also because of their cognitive constraints. The ability to implement appropriate accountability mechanisms to control decision-makers' propensity to optimize the present at the expense of the future is critical for the success of organizations.

Supplementary Information The online version contains supplementary material available at https://doi. org/10.1007/s00187-021-00330-7.

Acknowledgements The authors would like to thank Editor Thomas Günther and the two anonymous reviewers. We also thank Aljoša Valentinčič, Christian Lukas, Simon Čadež, Eva Boštjančič, David Naranjo-Gill, the participants of the annual EAA conference in Cyprus 2019 and the participants of the EIASM conference on performance measurement and management control in Nice in September 2019 for comments on this and earlier versions of the paper. We also thank the University of Ljubljana, School of Economics and Business for sponsoring the research. This work was supported by the Slovene research agency (ARRS) Grant P5-0161 (ML).

Funding This work was supported by the Slovene research agency (ARRS) Grant P5-0161 (ML).

Availability of data and material Data and experimental materials are available upon request from the corresponding author.

Code availability Code in $\mathrm{R}$ is available upon request from the corresponding author.

\section{Declarations}

Conflict of interest The authors have no conflicts of interest to declare that are relevant to the content of this article.

Open Access This article is licensed under a Creative Commons Attribution 4.0 International License, which permits use, sharing, adaptation, distribution and reproduction in any medium or format, as long as you give appropriate credit to the original author(s) and the source, provide a link to the Creative Commons licence, and indicate if changes were made. The images or other third party material in this article are included in the article's Creative Commons licence, unless indicated otherwise in a credit line to the material. If material is not included in the article's Creative Commons licence and your intended use is not permitted by statutory regulation or exceeds the permitted use, you will need to obtain permission directly from the copyright holder. To view a copy of this licence, visit http://creativecommons.org/licen ses/by/4.0/.

\section{References}

Ainslie, G. (1975). Specious reward: A behavioral theory of impulsiveness and impulse control. Psychological Bulletin, 82(4), 463-496.

Ainslie, G., \& Haslam, N. (1992). Hyperbolic discounting. In G. Loewenstein \& J. Elster (Eds.), Choice over time (pp. 57-92). Russell Sage Foundation.

Ainslie, G., \& Herrnstein, R. J. (1981). Preference reversal and delayed reinforcement. Animal Learning and Behaviour, 9(4), 476-482. https://doi.org/10.3758/BF03209777

Ardila, A., Rosselli, M., \& Strumwasser, S. (1991). Neuropsychological deficits in chronic cocaine abusers. International Journal of Neuroscience, 57(1-2), 73-79. https://doi.org/10.3109/0020745910 9150348 
Ashton, R. H. (1992). Effects of justification and a mechanical aid on judgment performance. Organizational Behavior and Human Decision Processes, 52, 292-306.

Baltussen, G., van den Assem, M., \& van Dolder, D. (2010). Risky choice in the limelight. Review of Economics and Statistics, 98(2), 318-332. https://doi.org/10.1162/REST_a_00505

Bartlett, G., Johnson, E., \& Reckers, P. (2014). Accountability and role effects in balanced scorecard performance evaluations when strategy timeline is specified. European Accounting Review, 23(1), $143-165$.

Baucells, M., \& Heukamp, F. H. (2012). Probability and time trade-off. Management Science, 58(4), 831-842. https://doi.org/10.1287/mnsc.1110.1450

Benartzi, S., \& Thaler, R. H. (1995). Myopic loss aversion and the equity premium puzzle. The Quarterly Journal of Economics, 110(1), 73-92.

Benzion, U., Rapoport, A., \& Yagil, J. (1989). Discount rates inferred from decisions: An experimental study. Management Science, 35(3), 270-284.

Bhojraj, S., \& Libby, R. (2005). Capital market pressure, disclosure frequency-induced earnings/cash flow conflict, and managerial myopia. The Accounting Review, 80(1), 1-20. https://doi.org/10. 2308/accr.2005.80.1.1

Bickel, W. K., Yi, R., Landes, R. D., Hill, P. F., \& Baxter, C. (2011). Remember the future: Working memory training decreases delay discounting among stimulant addicts. Biological Psychiatry, 69(3), 260-265. https://doi.org/10.1016/j.biopsych.2010.08.017

Botvinick, M. M., Braver, T. S., Barch, D. M., Carter, C. S., \& Cohen, J. D. (2001). Conflict monitoring and cognitive control. Psychological Review, 108, 624-652.

Braver, T. S. (2012). The variable nature of cognitive control: A dual mechanisms framework. Trends in Cognitive Sciences, 16, 106-113. https://doi.org/10.1016/j.tics.2011.12.010

Braver, T. S., Gray, J. R., \& Burgess, G. C. (2007). Explaining the many varieties of working memory variation: Dual mechanisms of cognitive control. In A. R. A. Conway, C. Jarrold, M. J. Kane, A. Miyake, \& J. Towse (Eds.), Variation in working memory (pp. 76-106). Oxford University Press.

Chang, L. J., Cheng, M. M., \& Trotman, K. T. (2013). The effect of outcome and process accountability on customer-supplier negotiations. Accounting, Organizations and Society, 38(2), 93-107.

Chapman, G. B. (1996). Temporal discounting and utility for health and money. Journal of Experimental Psychology: Learning, Memory, Cognition, 22(3), 771-791.

Chi, T., \& Fan, D. (1997). Cognitive limitations and investment "myopia." Decision Sciences, 28(1), 27-57. https://doi.org/10.1111/j.1540-5915.1997.tb01301.x

Chowdhury, J. (2011). Managerial myopia: A new look. College of Business. James Madison University. Harrisonburg, Virginia. http://cob.jmu.edu/jaideep/Jaideep_files/Myopia_12.09.11.pdf. Accessed 1 Apr

Cialdini, R. B., Levy, A., Herman, C. P., Kozlowski, L. T., \& Petty, R. E. (1976). Elastic shift of opinion: Determinants of direction and durability. Journal of Personality and Social Psychology, 34, 663-672. https://doi.org/10.1037/0022-3514.34.4.663

Clearfield, A. M. (2005). With friends like these, who needs enemies?" The structure of the investment industry and its reluctance to exercise governance oversight. Corporate Governance: An International Review, 13(2), 114-121.

Curley, S. P., Yates, J. F., \& Abrams, R. A. (1986). Psychological sources of ambiguity avoidance. Organizational Behavior and Human Decision Processes, 38(2), 230-256. https://doi.org/10.1016/07495978(86)90018-X

Dalla Via, N., Perego, P., \& van Rinsum, M. (2019). How accountability type influences information search processes and decision quality. Accounting, Organizations and Society, 75, 79-91. https:// doi.org/10.1016/j.aos.2018.10.001

Dasgupta, P., \& Maskin, E. (2005). Uncertainty and hyperbolic discounting. American Economic Review, 95(4), 1290-1299. https://doi.org/10.1257/0002828054825637

DeZoort, T., Harrison, P., \& Taylor, M. (2006). Accountability and auditors' materiality judgments: the effects of differential pressure strength on conservatism, variability, and effort. Accounting, Organizations and Society, 31, 373-390. https://doi.org/10.1016/j.aos.2005.09.001

Frederick, S., Loewenstein, G., \& O’Donoghue, T. (2002). Time discounting and time preference: a critical review. Journal of Economic Literature, 40(2), 351-401. https://doi.org/10.1257/0022051023 20161311

De Hoog, R., \& van der Wittenboer, G. (1986). Decision justification, information structure and the choice of decision rules. In B. Brehiner, H. Jungermann, P. Lourens, \& G. Sevon (Eds.), New direction in research on decision making. Elsevier Science. 
De Langhe, B., van Osselaer, S. M. J., \& Wierenga, B. (2011). The effects of process and outcome accountability on judgment process and performance. Organizational Behavior and Human Decision Processes, 115(2), 238-252.

De Martino, B., Kumaran, D., Seymour, B., \& Dolan, R. J. (2006). Frames, biases, and rational decisionmaking in the human brain. Science, 313(5787), 684-687. https://doi.org/10.1126/science.1128356

Edwards, M., \& Hulme, D. (1996). Too close for comfort? The impact of official aid on nongovernmental organizations. World Development, 24, 961-973.

Feng, C., Wang, H., Lu, N., Chen, T., He, H., Lu, Y., \& Tu, X. M. (2014). Log-transformation and its implications for data analysis. Shanghai Archives of Psychiatry, 26(2), 105-109. https://doi.org/10. 3969/j.issn.1002-0829.2014.02.009

Field, A. (2009). Discovering statistics using SPSS (Vol. 3, pp. 347-456). SAGE Publications. https://doi. org/10.1002/bjs.7040

Fox, J., \& Brown, D. L. (1998). The struggle for accountability: The World Bank, NGOs and grassroots movements. MIT Press.

Gigerenzer, G. (2007). Gut feelings: The intelligence of the unconscious. Penguin Group.

Gigler, F., Kanodia, C., Sapra, H., \& Venugopalan, R. (2014). How frequent financial reporting can cause managerial short-termism: An analysis of the costs and benefits of increasing reporting frequency. Journal of Accounting Research, 52(2), 357-387. https://doi.org/10.1111/1475-679X.12043

Glimcher, P. W., Dorris, M. C., \& Bayer, H. M. (2005). Physiological utility theory and the neuroeconomics of choice. Games and Economic Behavior, 52, 213-256.

Glimcher, P. W., Kable, J., \& Louie, K. (2007). Neuroeconomic studies of impulsivity: Now or just as soon as possible? American Economic Review, 97(2), 142-147. https://doi.org/10.1257/aer.97.2. 142

Gonzalez, C., Dana, J., Koshino, H., \& Just, M. (2005). The framing effect and risky decisions: Examining cognitive functions with fMRI. Journal of Economic Psychology, 26(1), 1-20. https://doi.org/ 10.1016/j.joep.2004.08.004

Graham, J. R., Harvey, C. R., \& Rajgopal, S. (2005). The economic implications of corporate financial reporting. Journal of Accounting and Economics, 40(1-3), 3-73. https://doi.org/10.3386/w10550

Green, L., \& Myerson, J. (1996). Exponential versus hyperbolic discounting of delayed outcomes: Risk and waiting time. American Zoologist, 36, 496-505.

Green, L., \& Myerson, J. (2004). A discounting framework for choice with delayed and probabilistic rewards. Psychological Bulletin, 130(5), 769-792. https://doi.org/10.1037/0033-2909.130.5.769

Green, L., Myerson, J., Holt, D., Slevin, J., \& Estle, S. (2004). Discounting of delayed food rewards in pigeons and rats: Is there a magnitude effect? Journal of the Experimental Analysis of Behavior, 81(1), 39-50. https://doi.org/10.1901/jeab.2004.81-39

Green, L., Myerson, J., \& McFadden, E. (1997). Rate of temporal discounting decreases with amount of reward. Memory and Cognition, 25(5), 715-723. https://doi.org/10.3758/BF03211314

Green, L., Myerson, J., \& Ostaszewski, P. (1999). Amount of reward has opposite effects on the discounting of delayed and probabilistic outcomes. Journal of Experimental Psychology: Learning, Memory, and Cognition, 25(2), 418-427. https://doi.org/10.1037/0278-7393.25.2.418

Halevy, Y. (2008). Strotz meets Allais: Diminishing impatience and the certainty effect. American Economic Review, 98(3), 1145-1162. https://doi.org/10.1257/aer.98.3.1145

Horgan, T., \& Timmons, M. (2011). Introspection and the phenomenology of free will: Problems and prospects. Journal of Consciousness Studies, 18(1), 180-205.

Huber, O., Bär, A. S., \& Huber, O. W. (2009). Justification pressure in risky decision making: Search for risk defusing operators. Acta Psychologica, 130, 17-24.

Huber, O., \& Seiser, G. (2001). Accounting and convincing: The effect of two types of justification on the decision process. Journal of Behavioral Decision Making, 14, 69-85.

Jermias, J. (2006). The influence of accountability on overconfidence and resistance to change: A research framework and experimental evidence. Management Accounting Research, 17, 370-388. https://doi.org/10.1016/j.mar.2006.03.003

Kahneman, D. (2003). Maps of bounded rationality: Psychology for behavioral economics. American Economic Review, 93(5), 1449-1475. https://doi.org/10.1257/000282803322655392

Kahneman, D., \& Tversky, A. (1979). Prospect theory: An analysis of decision under risk. Econometrica, 47(2), 263. https://doi.org/10.2307/1914185

Kahneman, D., \& Tversky, A. (1982). The subjective probability: a judgment of representativeness. In D. Kahneman, P. Slovic, \& A. Tversky (Eds.), Judgment under uncertainty: Heuristics and biases. Cambridge University Press. 
Kennedy, J. (1993). Debiasing audit judgment with accountability: a framework and experimental results. Journal of Accounting Research, 31(2), 231-245.

Kennedy, J. (1995). Debiasing the curse of knowledge in audit judgment. The Accounting Review, 70(2), $249-273$.

Kim, S., \& Trotman, K.T. (2015). The comparative effect of process and outcome accountability in enhancing professional scepticism. Auditing. https://doi.org/10.1111/acfi.12084

Klimoski, R. J., \& Inks, L. (1990). Accountability forces in performance appraisal. Organizational Behavior and Human Decision Processes, 45(2), 194-208. https://doi.org/10.1016/0749-5978(90) 90011-W

Kraft, A. G., Vashishtha, R., \& Venkatachalam, M. (2018). Frequent financial reporting and managerial myopia. The Accounting Review, 93(2), 249-275. https://doi.org/10.2308/accr-51838

Laibson, D. (1997). Golden eggs and hyperbolic discounting. The Quarterly Journal of Economics, 112(2), 443-478. https://doi.org/10.1162/003355397555253

Leary, M. R., \& Kowalski, R. M. (1990). Impression management: A literature review and a two component model. Psychological Bulletin, 107(1), 34-47. https://doi.org/10.1037/0033-2909.107.1.34

Lerner, J. S., \& Tetlock, P. E. (1999). Accounting for the effects of accountability. Psychological Bulletin, 125(2), 255-275. https://doi.org/10.1037/0033-2909.125.2.255

Libby, T., Salterio, S. E., \& Webb, A. (2004). The balanced scorecard: The effects of assurance and process accountability on managerial judgment. The Accounting Review, 79(4), 1075-1094.

Ličen, M., Slapničar, S., Slana Ozimič, A., Hartmann, F. G. H., Anticevic, A., \& Repovš, G. (2019) Social incentives shape neural circuits underlying cognitive control (September 1, 2019). Available at SSRN: https://www.papers.ssrn.com/sol3/papers.cfm?abstract_id=3448389. Accessed 1 Apr

Ličen, M., Hartmann, F., Repovš, G., \& Slapničar, S. (2016). The impact of social pressure and monetary incentive on cognitive control. Frontiers in Psychology, 7, 93. https://doi.org/10.3389/fpsyg.2016. 00093

Lion, R., \& Meertens, R. M. (2001). Seeking information about a risky medicine: Effects of risk-taking tendency and accountability. Journal of Applied Social Psychology, 31(4), 778-795.

Loewenstein, G., Rick, S., \& Cohen, J. D. (2008). Neuroeconomics. Annual Review of Psychology, 59, 647-672. https://doi.org/10.1146/annurev.psych.59.103006.093710

Lopez-Guzman, S., Konova, A. B., Louie, K., \& Glimcher, P. W. (2018). Risk preferences impose a hidden distortion on measures of choice impulsivity. PLoS ONE, 13(1), 1-18. https://doi.org/10.1371/ journal.pone.0191357

Luckman, A., Donkin, C., \& Newell, B. R. (2017). People wait longer when the alternative is risky: The relation between preferences in risky and inter-temporal choice. Journal of Behavioral Decision Making, 30(5), 1078-1092. https://doi.org/10.1002/bdm.2025

Lukas, C., Neubert, M. F., Schöndube, J. R. (2019b). Experimental evidence on project choice and accountability. Unpublished working paper. Presented in European Network in Experimental Accounting (ENEAR) conference, Maastricht, 6-7th July 2019.

Lukas, C., Neubert, M. F., \& Schöndube, J. R. (2019a). Accountability in an agency model: Project selection, effort incentives and contract design. Managerial and Decision Economics, 40, 150158. https://doi.org/10.1002/mde.2989

Madden, G. J., Begotka, A. M., Raiff, B. R., \& Kastern, L. L. (2003). Delay discounting of real and hypothetical rewards. Experimental and Clinical Psychopharmacology, 11(2), 139-145. https:// doi.org/10.1037/1064-1297.11.2.139

Mazur, J. E. (1984). Tests of an equivalence rule for fixed and variable reinforced delays. Journal of Experimental Psychology: Animal Behaviour Processes, 10, 426-436. https://doi.org/10.1037/ 0097-7403.10.4.426

Mazur, J. E. (1985). Probability and delay of reinforcement as factors in discrete-trial choice. Journal of the Experimental Analysis of Behavior, 43(3), 341-351. https://doi.org/10.1901/jeab.1985. 43-341

Mazur, J. (1987). An adjusting procedure for studying delayed reinforcement. The effect of delay and of intervening events on reinforcement valueIn M. L. Commons, J. E. Mazur, J. A. Nevin, \& H. Rachlin (Eds.), Quantitative analyses of behavior (Vol. 4, pp. 55-73). Erlbaum.

Mazur, J. E. (1988). Estimation of indifference points with an adjusting-delay procedure. Journal of the Experimental Analysis of Behavior, 49(1), 37-47. https://doi.org/10.1901/jeab.1988.49-37

Mazur, J. E., \& Coe, D. (1987). Tests of transitivity in choices between fixed and variable reinforcer delays. Journal of the Experimental Analysis of Behavior, 47(3), 287-297. https://doi.org/10. 1901/jeab.1987.47-287 
Mazur, J. E., Snyderman, M., \& Coe, D. (1985). Influences of delay and rate of reinforcement on discrete-trial choice. Journal of the Experimental Analysis of Behavior, 11(4), 565-575. https:// doi.org/10.1037/0097-7403.11.4.565

McClure, S. M., Cohen, J. D., Laibson, D. I., \& Loewenstein, G. (2004). Separate neural systems value immediate and delayed monetary rewards. Science, 306(5695), 503-507. https://doi.org/ 10.1126/science. 1100907

Merchant, K. A. (1990). The effects of financial controls on data manipulation and management myopia. Accounting, Organizations and Society, 15(4), 297-313. https://doi.org/10.1016/03613682(90)90021-L

Messier, W. F., Quick, L. A., \& Vandervelde, S. D. (2014), The influence of process accountability and accounting standard type on auditor usage of a status quo heuristic. Accounting, Organizations and Society, 39(1), 59-74.

Miller, K. D. (2002). Knowledge inventories and managerial myopia. Strategic Management Journal, 23(8), 689-706. https://doi.org/10.1002/smj.245

Mizik, N. (2010). The theory and practice of myopic management. Journal of Marketing Research, 47(4), 594-611. https://doi.org/10.1509/jmkr.47.4.594

Mizik, N., \& Jacobs, R. (2007). Myopic marketing management: Evidence of the phenomenon and its long-term performance consequences in the SEO context. Marketing Science, 26(3), 361-379. https://doi.org/10.1287/mksc.1060.0261

Narayanan, M. P. (1985). Managerial incentives for short-term results. Journal of Finance, 40(5), 1469. https://doi.org/10.1111/j.1540-6261.1985.tb02395.x

Pahlke, J., Strasser, S., \& Vieider, F. M. (2012). Risk-taking for others under accountability. Economics Letters, 114, 102-105. https://doi.org/10.1016/j.econlet.2011.09.037

Pahlke, J., Strasser, S., \& Vieider, F. M. (2015). Responsibility effects in decision making under risk. Journal of Risk and Uncertainty, 51(2), 125-146. https://doi.org/10.1007/s11166-015-9223-6

Pender, J. L. (1996). Discount rates and credit markets: Theory and evidence from rural India. Journal of Development Econonomics, 50(2), 257-296.

Pessoa, L. (2008). On the relationship between emotion and cognition. Nature Reviews. Neuroscience, 9, 148-158.

Prelec, D., \& Loewenstein, G. (1991). Decision making over time and under uncertainty: A common approach. Management Science, 37(7), 770-786.

Psychology Software Tools, Inc. [E-Prime 3.0]. (2016). http://www.pstnet.com. Accessed 1 Apr

Psychology Software Tools, Inc. [E-Prime Go 1.0]. (2020). Retrieved from http://www.pstnet.com. Accessed 1 Apr

Quinn, A., \& Schlenker, B. R. (2002). Can accountability produce independence? Goals as determinants of the impact of accountability on conformity. Personality and Social Psychology Bulletin, 28(4), 472-483. https://doi.org/10.1177/0146167202287005

R Core Team (2020). R: A language and environment for statistical computing. R Foundation for Statistical Computing, Vienna, Austria. https://www.R-project.org/. Accessed $1 \mathrm{Apr}$

Rachlin, H., \& Green, L. (1972). Commitment, choice, and self-control. Journal of the Experimental Analysis of Behavior, 17(1), 15-22. https://doi.org/10.1901/jeab.1972.17-15

Rachlin, H., Raineri, A., \& Cross, D. (1991). Subjective probability and delay. Journal of the Experimental Analysis of Behavior, 55, 233-244. https://doi.org/10.1901/jeab.1991.55-233

Radu, P. T., Yi, R., Bickel, W. K., Gross, J. J., \& McClure, S. M. (2011). A mechanism for reducing delay discounting by altering temporal attention. Journal of the Experimental Analysis of Behavior, 96(3), 363-385. https://doi.org/10.1901/jeab.2011.96-363

Redelmeier, D. A., \& Heller, D. N. (1993). Time preference in medical decision making and costeffectiveness analysis. Medical Decision Making, 13(3), 212-217.

Richards, J. B., Mitchell, S. H., De Wit, H., \& Seiden, L. S. (1997). Determination of discount functions in rats with an adjusting-amount procedure. Journal of the Experimental Analysis of Behavior, 67(3), 353-366. https://doi.org/10.1901/jeab.1997.67-353

Rotter, J. B. (1954). Social learning and clinical psychology. Englewood Cliffs. Prentice-Hall.

Samuelson, P. A. (1937). A note on measurement of utility. The Review of Economic Studies, 4, 155161. https://doi.org/10.2307/2967612

Shiv, B., Loewenstein, G., \& Bechara, A. (2005). The dark side of emotion in decision-making: When individuals with decreased emotional reactions make more advantageous decisions. Cognitive Brain Research, 23, 85-92. 
Simon, S. L., Domier, C. P., Sim, T., Richardson, K., Rawson, R. A., \& Ling, W. (2002). Cognitive performance of current methamphetamine and cocaine abusers. Journal of Addictive Diseases, 21(1), 61-74. https://doi.org/10.1300/J069v21n01_06

Stein, J. (1989). Efficient capital markets, inefficient firms: A model of myopic corporate behavior. The Quarterly Journal of Economics, 104(4), 655-669. https://doi.org/10.2307/2937861

Tetlock, P. E. (1983). Accountability and complexity of thought. Journal of Personality and Social Psychology, 45, 74-83. https://doi.org/10.1037/0022-3514.45.1.74

Tetlock, P. E. (1985). Accountability: The neglected social context of judgment and choice. Research in Organizational Behavior, 7, 297-332.

Tetlock, P. E., \& Kim, J. I. (1987). Accountability and judgment processes in a personality prediction task. Journal of Personality and Social Psychology, 52(4), 700-709. https://doi.org/10.1037/ 0022-3514.52.4.700

Tetlock, P. E., Skitka, L., \& Boettger, R. (1989). Social and cognitive strategies for coping with accountability: Conformity, complexity, and bolstering. Journal of Personality and Social Psychology, 57(4), 632-640. https://doi.org/10.1037/0022-3514.57.4.632

Thaler, R. H. (1981). Some empirical evidence on dynamic inconsistency. Economic Letters, 8(3), 201-207.

Thaler, R. H., \& Sunstein, C. R. (2003). Libertarian Paternalism. American Economic Review, 93(2), 175-179. https://doi.org/10.1257/000282803321947001

Thaler, R. H., \& Sunstein, C. R. (2008). Nudge: improving decisions about health, wealth, and happiness. Yale University Press. ISBN 978-0-14-311526-7.

Thaler, R. H., Tversky, A., Kahneman, D., \& Schwartz, A. (1997). The effect of myopia and loss aversion on risk-taking: An experimental test. Quarterly Journal of Economics, 112(2), 647-661. https://doi.org/10.1162/003355397555226

Thanassoulis, J. (2012). The case for intervening in bankers' pay. Journal of Finance, 67(3), 849-895. https://doi.org/10.1111/j.1540-6261.2012.01736.x

Tong, J. \& Zhang, F. (2021). Do capital markets punish managerial myopia? Evidence from myopic R\&D cuts. Forthcoming at Journal of Financial and Quantitative Analysis. https://www.jfqa. org/2021/02/18/do-capital-markets-punish-managerial-myopia-evidence-from-myopic-rd-cuts. Accessed 1 Apr

Trautmann, S. T., Vieider, F. M., \& Wakker, P. P. (2008). Causes of ambiguity aversion: Known versus unknown preferences. Journal of Risk and Uncertainty, 36(3), 225-243. https://doi.org/10. 1007/s11166-008-9038-9

Tversky, A., \& Kahneman, D. (1974). Judgment under uncertainty: Heuristics and biases. Science, 185(4157), 1124-1131. https://doi.org/10.1126/science.185.4157.1124

Vanderveldt, A., Oliveira, L., \& Green, L. (2016). Delay discounting: Pigeon, rat, human-does it matter? Journal of Experimental Psychology: Animal Learning and Cognition, 42(2), 141-162. https://doi.org/10.1037/xan0000097

Vieider, F. M. (2009). The effect of accountability on loss aversion. Acta Psychologica, 132(1), 96-101. https://doi.org/10.1016/j.actpsy.2009.05.006

Vieider, F. M. (2011). Separating real incentives and accountability. Experimental Economics, 14, 507518. https://doi.org/10.1007/s10683-011-9279-3

Weigold, M. F., \& Schlenker, B. R. (1991). Accountability and risk taking. Personality and Social Psychology Bulletin, 17, 25-29. https://doi.org/10.1177/0146167291171004

Publisher's Note Springer Nature remains neutral with regard to jurisdictional claims in published maps and institutional affiliations. 